\title{
Design and Analysis of Hybrid Energy Storage System in DC Microgrid
}

\author{
Manish Dhapani \\ Research Scholar \\ Department of Electrical and Electronics Engineering \\ Radharaman Engineering College \\ Bhopal, India \\ manish.dhapani@gmail.com
}

\author{
Prof. Durgesh Vishwakarma \\ Assistant Professor \\ Department of Electrical and Electronics Engineering \\ Radharaman Engineering College \\ Bhopal, India
}

\begin{abstract}
A microgrid is a restricted gathering of power sources and loads that typically work associated with and coordinated with the conventional wide region simultaneous network (macrogrid), as the quantity of DC-creating sustainable power sources is higher when contrasted with air conditioning producing sources, lesser converter units are required. This builds the general proficiency of DC microgrid. A DC small scale lattice framework is utilizing a force organize that empowers the presentation of a lot of sun oriented vitality utilizing circulated photovoltaic age units. This paper manages the plan and execution examination of a DC microgrid with batterysupercapacitor vitality stockpiling framework under factor supercapacitor working voltage. MATLAB 9.4 is utilizing to execute the model and investigation.
\end{abstract}

Index Terms - DC, Microgrid, Energy, Battery, Supercapacitor.

\section{INRODUCTION}

WSN tremendous headways happened throughout the following century: the advancement of enlistment and simultaneous machines, electric meters, high voltage transmission, gas turbines, atomic reactors, wind turbines, and sunlight based photovoltaic's, to give some examples. These innovations were gone to the turn of events, headway, and development of "the matrix;" the arrangement of enormous scope incorporated age associated with vitality clients through a system of transmission and circulation. In any case, while an apparently perpetual flexibly of exertion and subsidizing was being filled "the biggest machine at any point worked", lately another pattern in research began, as some investigated the favorable circumstances to moving the other way: circulated, decentralized, nearby lattices: microgrids.
Sunlight based photovoltaic and energy components produce dc current legitimately, and many breeze power frameworks can without much of a stretch produce dc current, or are interfaced to the air conditioner lattice through a DC connect.

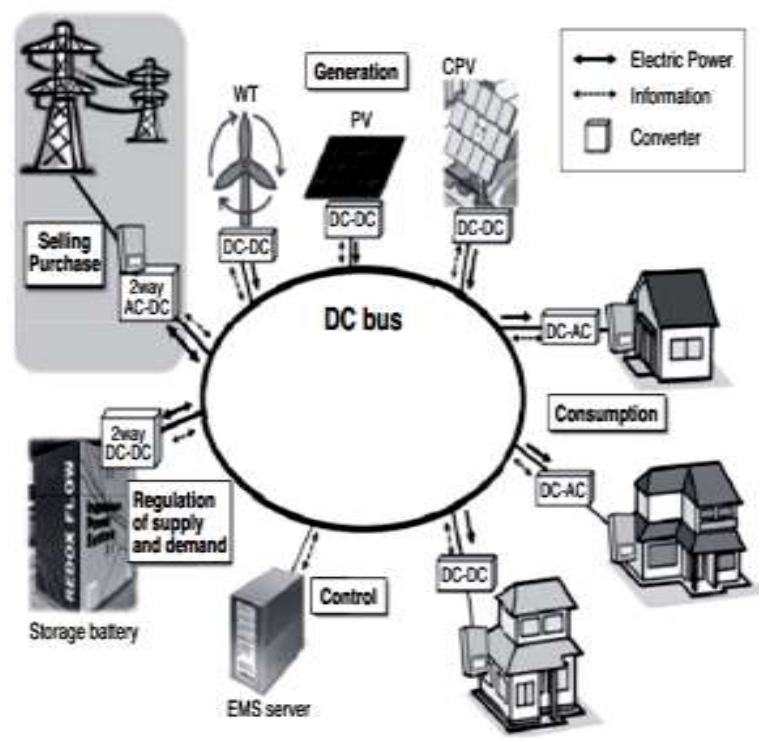

Figure 1: Schematic diagram of a DC microgrid system

Many types of electrical loads use dc power natively

The Most of hardware, (for example, PCs, servers, and televisions) use dc power. Driven lights additionally use dc power locally. Numerous kinds of engines and drives (particularly factor speed drives) use dc power. In every one of the three cases, these sources, stockpiling frameworks, and burdens require converters at whatever point they interface with air conditioning power frameworks; accordingly chang- 
ing to a dc power framework disposes of the requirement for such converters, killing the misfortunes which are inborn in an influence transformation. Until now, key territories of usage for dc power frameworks have included server farms, rocket, planes, shipboard force frameworks, foothold power frameworks (for trains, streetcars, cable cars, and so on), and media transmission foundation. Advancemnts in these regions have prodded research on dc microgrids, and sometimes gave proving grounds to setting up utilitarian $\mathrm{dc}$ microgrids (especially on account of server farms and telecoms, where the cost investment funds potential is huge).

\section{BACKGROUND}

S. Sinha et al., [1] the target of this work is to introduce a near investigation of charging and releasing procedure of both battery and SC banks and consequently comprehend their application zones in a DC microgrid. Likewise the pace of charge-release and its control to forestall over charging or under-releasing of the capacity gadgets is introduced here.

N. MENG, Libei et al., [2] proposed an improved hang control dependent on mixture pay is received to acknowledge transport voltage soundness and force partaking in the framework. At last, reproduction examination is done, and the test results confirm the plausibility of the control procedure referenced previously.

P. Mohammadi et al., [3] in this work, novel DC-DC single-inductor twofold info bidirectional converter is introduced for incorporating the HESS to the DC smaller scale matrix. The consistent state investigation of proposed converter is introduced. Little sign model of the converter is inferred out and control system is illustrated. At long last, definite reproductions are done in MATLAB SIMULINK. The ability of proposed converter for legitimate force sharing between the battery and the super capacitor is approved through reproductions.

P. Goleij et al., [4] proposed new hybridization idea for tackle the negative impacts of symphonious burdens and nonlinear burden is proposed. In this procedure super capacitor (SC) is utilized for remunerate the swaying that create by symphonious burdens. Likewise, proposed procedure improves framework execution under burden changes and varieties. To research the impact of sounds and affirm the proposed technique, reproduction of a half and half framework has been actualized in MATLAB/SIMULINK condition. The reenactment results demonstrate the adequacy of the proposed system.

L. Zekun et al., [5] proposed technique which can keep away from the pointless exchanging between the ace and slave source, guarantee the framework stable under enormous aggravations and help the framework rapidly come back to the steady state. The standard and security control methodology are basic and can be effectively executed. Reenactment results show that the security rule and the con- trol methodology are compelling.

T. K. Roy et al., [6] this work presents a technique for dynamic solidness examination of crossover islanded DC microgrids utilizing nonlinear backstepping controllers (NBCs) with various microgrid parts. The fundamental segments of the DC microgrid are a sun based photovoltaic framework, a diesel generator with rectifier, loads, and a battery vitality stockpiling framework.

S. Gupta et al., [7] presents the microgrid framework which comprises of a Vitality Stockpiling Framework (ESS) which is associated by means of a bidirectional buck-help converter. The general steadiness of the microgrid is kept up by the control activity of the ESS. DC microgid framework have been investigated and reenactment done utilizing MATLAB.

U. Manandhar et al., [8] proposed control approach the voltage blunder term and the uncompensated force from the battery is added to the supercapacitor current reference to accomplish quicker DC connect voltage rebuilding and less worry in the battery framework. The framework boundaries plan and shut circle framework steadiness examination of the proposed control approach are talked about in detail in the paper. The viability of the proposed control approach is confirmed by reenactment examines.

Q. Xu et al., [9] execute the proposed EDC strategy, a nitty gritty structure technique is proposed to accomplish the control goals of stable activity, voltage guideline, and dynamic current sharing. Framework dynamic model and significant impedances are determined and itemized recurrence space investigation is performed. Additionally, the framework level dependability examination is researched and framework development with the proposed strategy is delineated. The two reproductions and analyses are directed to approve the viability of the proposed control procedure and diagnostic outcomes.

H. Zheng et al., [10] proposed the proposed half and half air conditioning/DC miniaturized scale network structure is sensible, and the control system and execution of the parts is acceptable. The entire framework has quick reaction speed, and can well fulfill the necessity of framework security and strength.

P. H. Shaikh et al., [11] this work presents the presentation examination of an incorporated sustainable power source based force age framework with DC miniaturized scale lattice arrangement. The planned framework involves wind generator (WG) framework, photovoltaic (PV) boards, battery, charge controllers and DC loads as its significant parts.

\section{Proposed Model}

The significant commitment of this exploration work is to precise displaying of DC microgrid with hybrid vitality stockpiling framework (HESS) for execution improve- 
ment so it very well may be progressively useable in home and mechanical applications.

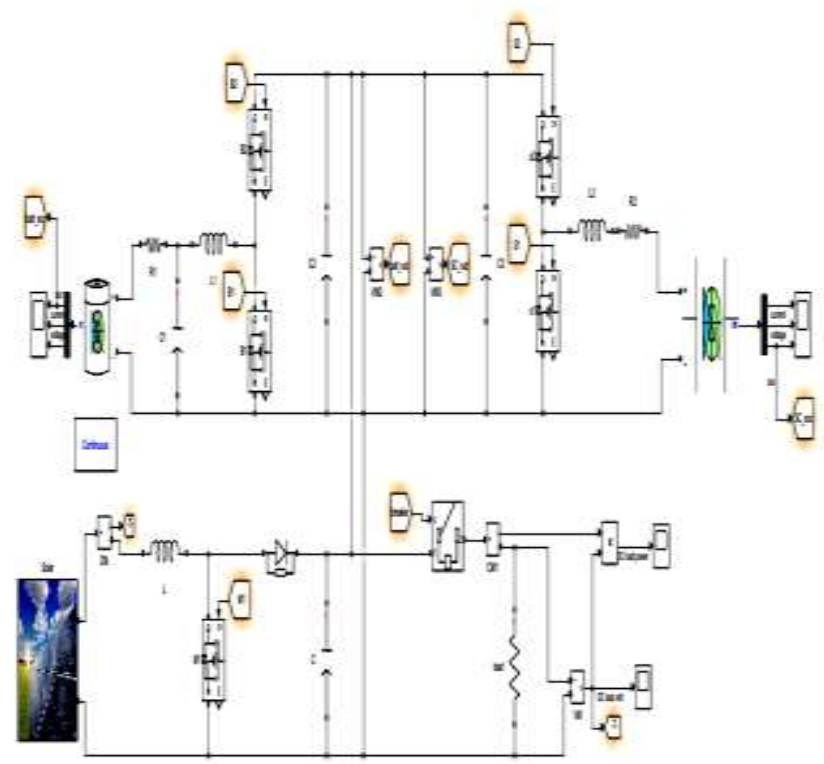

Figure 2: Proposed Model

Proposed model consist various sub models which is described in details.

\section{Sub-Modules}

- Solar power

- $\quad$ MPPT Algorithm

- $\quad$ PWM Switching

- Boost converter

- Bidirectional converter and mode of operation

- Battery

- Super capacitor

There are four potential working modes. The control methodology manages the DC connect voltage in all the four working modes utilizing battery or PV source. The four working modes are clarified underneath.

(1) Battery Releasing Mode (BDM): In this mode, the PV power is not exactly the heap power and the battery $\mathrm{SoC}$ is inside cutoff points. Accordingly, the battery releases to manage the DC interface voltage.

(2) Load Shedding Mode (LSM): In this mode, the $\mathrm{PV}$ power is not exactly the heap power and the battery is completely released. Hence the heaps are disengaged and the accessible force is utilized to charge the battery.

(3) Battery Charging Mode (BCM): In this mode, the PV power is more than the heap power and the battery
SoCis inside cutoff points. Subsequently, the battery directs the DC interface voltage by accusing of the abundance power accessible.

(4) PV Off-MPPT Mode (POM): In this mode, the battery has completely energized, along these lines, the PV is worked in off-MPPT mode to manage the DC transport voltage.

Photovoltaic (PV), smaller scale matrices, battery cells and vitality stockpiling, and other potential DERs yield either straightforwardly DC or air conditioning with fluctuant recurrence and voltage. Accordingly, the above yields should be changed into DC, and afterward access to conventional air conditioning power framework through the inverter. DC dissemination framework encourage DERs legitimately access to control network.

\section{SIMULATION AND RESULT ANALYSIS}

The usage and recreation of the proposed model is done over MATLAB 9.4.0.813654 (R2018a). The different electrical tool stash and squares encourages us to utilize the capacities accessible in MATLAB Library for different structure technique.

MODE(i) Battery Releasing Mode (BDM): In this mode, the PV power is not exactly the heap power and the battery $\mathrm{SoC}$ is inside cutoff points. In this manner, the battery releases to control the DC interface voltage.

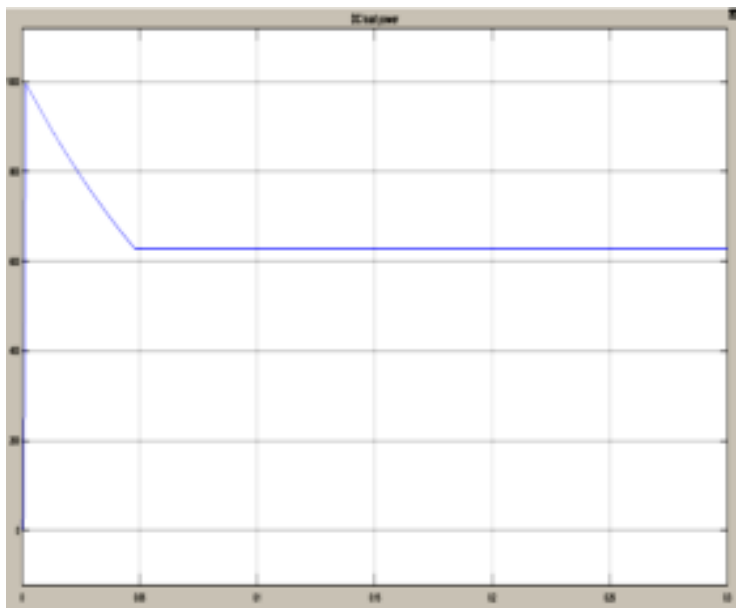

Figure 3: DC Load Power

Figure 3 is showing DC load power graph. Here $\mathrm{X}$ axis is denoting as a time scale and $\mathrm{Y}$ axis is denoting as a value of power. So load power value is $630 \mathrm{~W}$. 


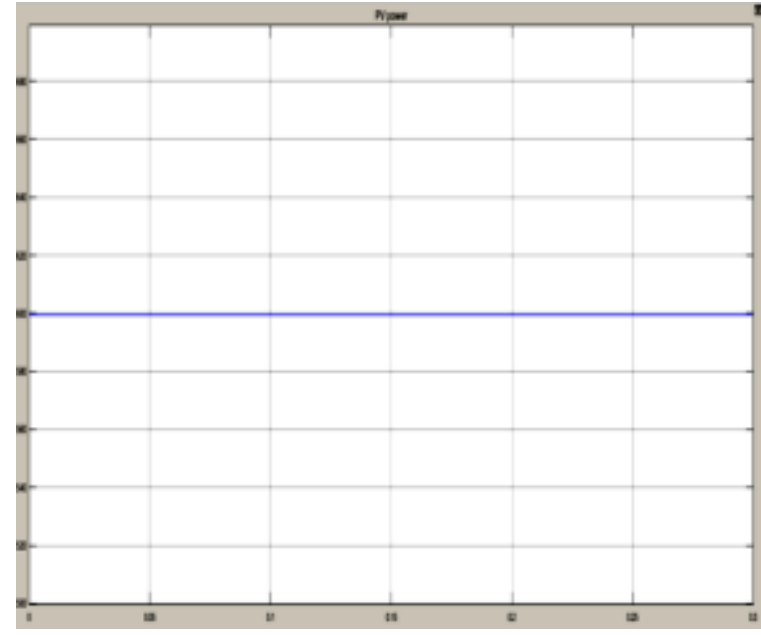

Figure 4: Solar (PV) Power

Figure 4 is showing solar power graph. Here $\mathrm{X}$ axis is denoting as a time scale and $\mathrm{Y}$ axis is denoting as a value of $\mathrm{PV}$ power. So Solar (PV) power value is $600 \mathrm{~W}$. Here, the solar power is 600 watts < load power is 630 watts

Mode(ii) Load Shedding Mode (LSM): In this mode, the PV power is not exactly the heap power and the battery is completely released. In this manner the heaps are disengaged and the accessible force is utilized to charge the battery..

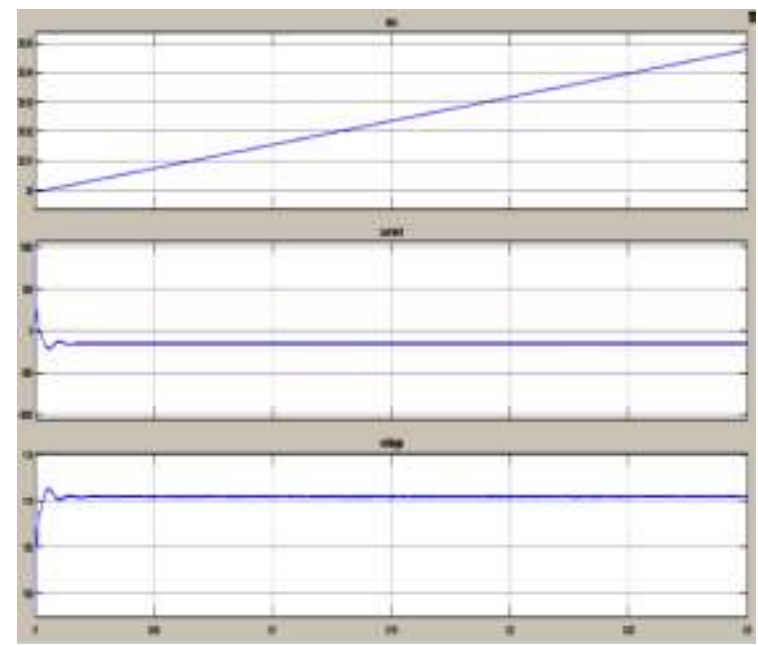

Figure 5: Battery (SOC, Current, Voltage)

Figure 5 is battery state of charge, voltage and current graph. Here $\mathrm{X}$ axis is denoting as a time scale and $\mathrm{Y}$ axis is denoting as a state of charge, value of current and voltage. Here, the battery is discharged below the lower limit.
MODE(iii) Battery Charging Mode (BCM): In this mode, the PV power is more than the heap power and the battery SoC is inside cutoff points. In this way, the battery directs the DC interface voltage by accusing of the overabundance power accessible.

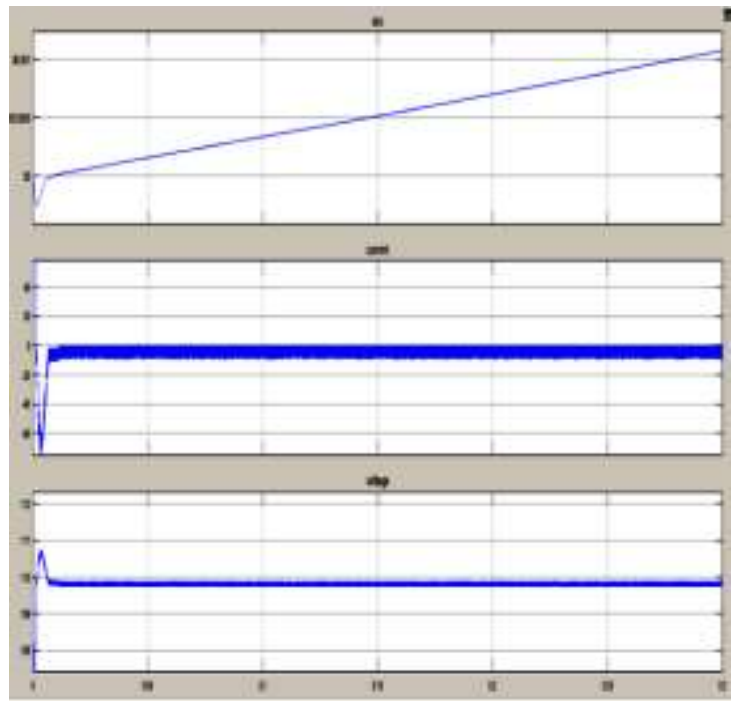

Figure 6: Battery (SOC, Current, Voltage)

Mode(iv) PV Off-MPPT Mode (POM): In this mode, the battery has completely energized, subsequently, the PV is worked in off-MPPT mode to manage the DC transport voltage.

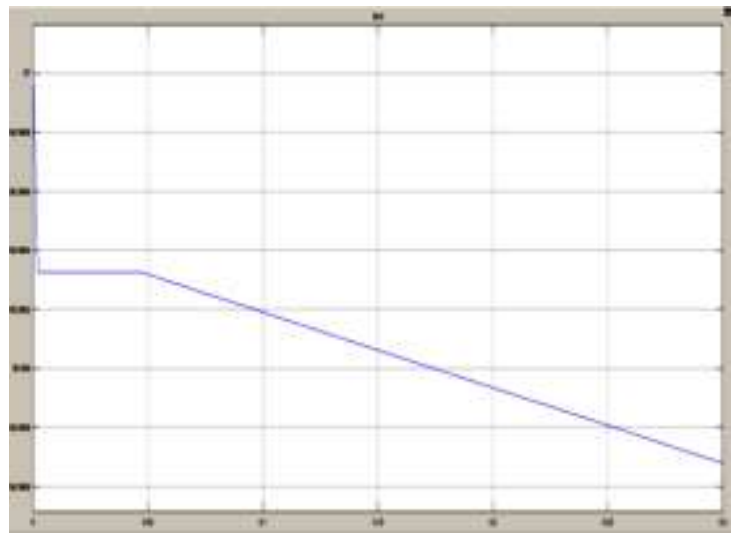

Figure 7: Battery

Figure 7 is showing battery state of charge. Here $\mathrm{X}$ axis is denoting as a time scale and $\mathrm{Y}$ axis is denoting as charge percentages. Here, the battery is fully charged soc $>95 \%$. 
Table 1: Comparison chart of proposed work with Base Work

\begin{tabular}{|c|c|c|c|}
\hline $\begin{array}{l}\text { Sr } \\
\text { No. }\end{array}$ & Parameters & $\begin{array}{l}\text { Previous } \\
\text { Work }\end{array}$ & $\begin{array}{l}\text { Proposed } \\
\text { Work }\end{array}$ \\
\hline 1 & $\begin{array}{l}\text { Battery Voltage (Dis- } \\
\text { charge) }\end{array}$ & $100 \mathrm{~V}$ & $110 \mathrm{~V}$ \\
\hline 2 & $\begin{array}{l}\text { Supercapacitor Voltage } \\
\text { (Discharge) }\end{array}$ & $111 \mathrm{~V}$ & $112-120 \mathrm{~V}$ \\
\hline 3 & $\begin{array}{ll}\text { Battery } & \text { Voltage } \\
\text { (Charge) } & \end{array}$ & $112 \mathrm{~V}$ & $110-120 \mathrm{~V}$ \\
\hline 4 & $\begin{array}{l}\text { Supercapacitor Voltage } \\
\text { (Charge) }\end{array}$ & $118 \mathrm{~V}$ & $112-120 \mathrm{~V}$ \\
\hline 5 & Switch & IGBT & MOSFET \\
\hline 6 & Controller & $\begin{array}{l}\text { PI, Buck } \\
\text { and Boost }\end{array}$ & $\begin{array}{l}\text { Bi- } \\
\text { directional }\end{array}$ \\
\hline 7 & State of Charge (SOC) & 20 to $100 \%$ & $95 \%$ \\
\hline 8 & Mode of operation & 2 & 4 \\
\hline
\end{tabular}

Therefore proposed model simulation result for performance is better than previous model in terms battery, load, and super capacitor. Proposed model gives significant improved results.

\section{Conclusion}

The impact of super capacitor voltage minor departure from the soundness of DC miniaturized scale network is dissected with its precise little sign model. An ideal super capacitor voltage based DC connect voltage controller HESS model structure technique is ace presented to guarantee the adequate voltage and current strength at all super capacitor voltages. The reproduction and trial results affirmed that the proposed structure gives execution than that of the traditional plan. In this manner, the proposed model structure accomplishes better powerful reaction over a wide scope of super capacitor working voltages.

\section{REFERENCES}

1. S. Sinha, A. K. Sinha and P. Bajpai, "Analysis of hybrid storage system in DC microgrid," 2016 21st Century Energy Needs - Materials, Systems and Applications (ICTFCEN), Kharagpur, 2016, pp. 1-5, doi: 10.1109/ICTFCEN.2016.8052754.
2. N. MENG, Libei, L. Jiahao, H. Jianhui and Susu, "Coordinated operation control strategy and droop improvement method for DC microgrid," 2018 International Conference on Power System Technology (POWERCON), Guangzhou, 2018, pp. 1214-1223.

3. P. Mohammadi, J. S. Moghani and G. B. Gharehpetian, "A Novel DC-DC Single-inductor Double-Input Bidirectional Converter for Hybrid Energy Storage System in DC-Micro Grid," 2018 Smart Grid Conference (SGC), Sanandaj, Iran, 2018, pp. 1-6.

4. P. Goleij, S. HajiAghasi and A. Salemnia, "A New Hybridization Concept for Distributed Generation and Microgrids under Harmonic and Nonlinear Loads," 2018 Smart Grid Conference (SGC), Sanandaj, Iran, 2018, pp. 1-6.

5. L. Zekun, P. Wei and K. Li, "Large-disturbance Stability Analysis of DC Microgrid with Constant Power Load and its Transient Voltage Stability Control Strategy," 2018 China International Conference on Electricity Distribution (CICED), Tianjin, 2018, pp. 1686-1690.

6. T. K. Roy and M. A. Mahmud, "Dynamic Stability Analysis of Hybrid Islanded DC Microgrids Using a Nonlinear Backstepping Approach," in IEEE Systems Journal, Vol. 12, No. 4, pp. 3120-3130, Dec. 2018.

7. S. Gupta, D. M. S. Das, and D. Mishra, "Modeling and Simulation of Hybrid Wind/Photovoltaic for Improvement of Reliability of The DC Microgrid", IJOSCIENCE, Vol. 4, No. 8, pp. 1-7, Aug. 2018. DOI:https://doi.org/10.24113/ijoscience.v4i8.15.

8. U. Manandhar, B. Wang, A. Ukil, G. H. Beng, N. R. Tummuru and S. K. Kollimalla, "A new control approach for PV system with hybrid energy storage system," IECON 2017 - 43rd Annual Conference of the IEEE Industrial Electronics Society, Beijing, 2017, pp. 2739-2743.

9. Q. Xu et al., "A Decentralized Dynamic Power Sharing Strategy for Hybrid Energy Storage System in Autonomous DC Microgrid," in IEEE Transactions on Industrial Electronics, Vol. 64, No. 7, pp. 5930-5941, July 2017. doi: 10.1109/TIE.2016.2608880

10. H. Zheng, H. Ma, K. Ma and Z. Bo, "Modeling and analysis of the AC/DC hybrid micro-grid with bidirectional power flow controller," 2017 China International Electrical and Energy Conference (CIEEC), Beijing, 2017, pp. 280-284.

11. P. H. Shaikh, T. Jan, A. R. Solangi, Z. H. Leghari, A. A. Baloch and M. A. Uqaili, "Performance analysis of windphotovoltaic-battery based DC microgrid setup for off-grid applications," 2017 IEEE 3rd International Conference on Engineering Technologies and Social Sciences (ICETSS), Bangkok, 2017, pp. 1-7.

12. S. Kotra, M. K. Mishra and N. P. Chaithanya, "Design and small signal analysis of DC microgrid with hybrid energy storage system," 2017 IEEE PES Asia-Pacific Power and Energy Engineering Conference (APPEEC), Bangalore, 2017, pp. 1-6 